\title{
The Construction of Interactive Teaching Mode under the Network Environment
}

\author{
Ying Luo ${ }^{1, \text { a }}$, Miaomiao $\mathrm{Li}^{2, \mathrm{~b}}$ \\ ${ }^{1}$ TVET Research Institute, Jiangxi Science \& Technology Normal University, Nanchang, China \\ ${ }^{2} E d u c a t i o n$ School, Jiangxi Science \& Technology Normal University, Nanchang, China \\ amooonly@126.com; bLiMiaomiao0710@163.com
}

Keywords: network environment; interactive teaching mode; interaction-type.

\begin{abstract}
It is emphasized in the new course standard, the teaching course should be one course that teachers and students exchange each other, interact actively and develop mutually. The writer has made a discussion on the "interaction-type" teaching mode that teachers and students exchange and share equally in teaching practice. Each of students has the chance to make a special sound to show the crash of ideas, to feel the happiness of the spirit encounter and learning and share the experience of success.
\end{abstract}

\section{Introduction}

Network teaching is a teaching activity with the computer network as the main medium. In the usual sense, teachers and students are separated from each other, and the network interaction is the main means of information exchange in teaching. Interaction is the word with high frequency appearing in the field of modern network education. At present, many colleges have formed the campus network, and network technology provides the possibility for the communication and interaction between teachers and students. In order to better play the role of network teaching environment to promote students' self development, it is necessary to try to construct the interactive teaching mode.

\section{Characteristics of interactive model under the network environment}

From the teaching content, network education information is boundless, so the students can select the knowledge and information according to personal interests and hobbies or need. In another word, the students can not accept knowledge passively any longer, but choose and study actively, which fully mobilize the initiative consciousness of students to explore, learn, analyze, and solve problems, and maximize the individual learning potential.

From the teaching time and space, interactive teaching activities under the network environment are unrestricted by the time and space, and have the indirect and subtle characteristics. The exchange process, not affected by the affective factors, is often achieved by text, voice, image, graphic and other symbols, and is different from the direct interaction in traditional classroom through language, movement and expression.

From the view of teaching process and teaching effect, interactive teaching is easier to achieve real-time communication and feedback between teachers and students. Teachers can undertake teaching for virtual group or the individual, and highlight the student-oriented education concept in the process of teaching, so as to truly teach students in accordance with their aptitude.

From the relationship between teachers and students, it can be one to one, namely the form of individual counseling or individual instruction; it can be one to many, that is, one teacher undertakes teaching for many students at the same time; it can also be many to one, that is, many online learners turn to one teacher, in which the various corresponding relations provide the possibility for learning guidance suitable to their characteristics. 
From the teaching method, interactive teaching is mainly embodied in the interaction between teachers and students - between students with students - between human and computers. Under the network environment, teachers can vividly present the abstract knowledge through various forms by using video and audio technology, to improve the learning efficiency and reduce the burden of teachers and students.

\section{Requirements of interactive teaching mode}

Interactive teaching mode aims to arouse students' interest in learning, promote them to think, and deepen their understanding and mastery the knowledge. Implementing interactive teaching has the following requirements.

First, teachers should prepare lessons fully and design teaching carefully. As teachers, they should not only master the basic knowledge, but also be familiar with the knowledge and information in related fields, especially the related material and data enriching students' knowledge and arousing students' interest. Before class, teachers should design and preview the teaching contents and ways according to the teaching contents and features, and prepare the materials and props, such as video files, cards and notes needed in co splay, etc.

Second, teachers should pay attention to accumulate case materials. Case teaching is helpful for students to understand and grasp knowledge, but whether the case is suitable needs teachers' professional judgment. Teachers can not echo what the books say according to the textbooks, but should search and accumulate with the objective in the daily reading, study and life, and choose suitable case in class, even modify or deduct the case according to students' understanding.

Third, teachers should have good classroom control ability. The lecture is different from the stage performance and not teachers' monologue, but needs the interaction with students. This requires teachers to control the teaching process and mobilize the classroom atmosphere by relying on their own knowledge and experience. By clever questioning, teachers can tell some small stories related to classroom content timely, say a few words to eliminate fatigue or cause students' attention, or stop lecturing to apply pressure to active classroom atmosphere when students lay their heads together.

Fourth, teachers' role should be played scientifically. Teaching and learning is a contradiction in the process of teaching. In this contradiction, teaching is the main aspect and playing the leading role of teachers is the key to achieve teaching purposes; the crucial role of teachers is more reflected in guiding, coaching and inspiring students' intrinsic motivation and playing their independence and creativity. Therefore, teachers should fully understand students' learning situation, and pay attention to the performance and state of students in the classroom, so as to adjust teaching methods timely to guide them to learn actively. Teachers must clearly recognize that, the student is the subject of learning and development, so they must adhere to the principle of combining teachers' leading and students' body. They should encourage those students who always have distinctive and unique insight and focus on training their critical and creative thinking.

Fifth, it needs modern teaching facilities. The development of interactive teaching mode is not only the verbal communication between teachers and students, but also needs the necessary teaching means to achieve the desired effect. (1) The multimedia teaching equipment. The development of modern electronic technology makes the multimedia equipment enter into teaching, and lets traditional teaching method undergo fundamental change. The advantages of optical, acoustic and electric integration of multimedia devices not only reduce the workload of teachers' classroom writing, the more important is helpful to attract students' attention due to the change of classroom environment and to carry out classroom discussion or cases. (2) Simulation laboratory. Some professional courses can be carried out through simulation laboratory under the guidance of teachers, which can deepen the understanding of theoretical knowledge and exercise their ability. At the same time, it is conducive to further deepen exchanges and communication between teachers and students and enhance students' learning interest and enthusiasm. (3) Common aids. Common aids, such as 
chart, photographs, plate painting, specimens, models, objects, etc, still have superiority of convenience, economy and intuition, and also can play a role in mobilizing students' interest.

\section{Strategies of interactive teaching mode}

Interactive teaching mode is mainly displayed in reading, discussing, speaking and practice. Reading is to guide students to read the text, landscape description, audio and video data, charts and other data and enhance students' perception on related things by obtaining needed information through reading. Discussing is to organize students to discuss through reading, and let them summarize the laws of things, understand its usefulness in the production and life, and enhance the intrinsic link with other disciplines. Speaking means that, on one hand, let students speak under the guidance of teachers to improve students' analytical ability and verbal ability, one the other hand, teachers' speaking can make students know classroom teaching objectives, rationalize the ideas of whole lesson, teach good study methods and memory method, develop ideas and cultivate innovation. Practice is to design a variety of training questions interspersed throughout the classroom teaching process aiming at the teaching objectives. In the setting of the training title, the difficulty should have a certain level to make most students achieve success in training.

To achieve the above requirements, the following strategies can be adopted.

Creating atmosphere. Create free and equal atmosphere of "student-student" and "teacher-student" through the forms of group discussions, group debate, and speech. Mutual questioning and help between students can let them learn to think, solve problems, and develop thinking, so as to achieve the purpose of learning. In this process, the teachers' participation is essential. They should capture wonderful place of their answer and give them approval timely.

Teachers' guidance. Teachers' role is to guide students to continue to ask questions and to make the learning process become the process of asking and solving questions; teachers' role is to guide students to collect and use learning resources; teachers' role is to help students to design appropriate learning activities; teachers' role is to choose different learning ways according to different learning contents, such as, acceptance, exploration, imitation and experience, etc, to make students' learning become rich and personal; teachers' role is to create positive psychological atmosphere supporting students' learning; teachers' role is to help students to evaluate the learning process and outcome.

Tiered progressive strategy. In the interactive teaching, it emphasizes on students' ability of independence, so in the learning, many problems and difficulties will produce inevitably, which requires teachers to guide students consciously and solve problems and difficulties encountered progressively.

Scouring strategy. Interactive teaching is to prevent teachers to undertake cramming education; it requires teachers not to speak as much as possible and to allow students to discover as much as possible, that is to say, teachers' speaking is the guidance and summary of students' deficiencies.

Teachers' awareness strategy. (1) Occupational awareness. The profession of teacher serves for students and is responsible for their development. That is to say, all is conducive to students' growth and development. (2) Citizenship. Because teacher is an ordinary citizen and student is a present or future citizen group, their legal status is equal and the legal rights and obligation should be fully reflected in the teachers' body. Teacher has no right to be superior to the students. (3) Role reversing awareness. As a teacher, he should be scrupulous with study and present the example to students; after class, he should be able to walk into students and become their close friend and partner. That is the integration of lively and serious, and tension and leisure.

\section{Conclusion}

The interactive teaching mode under the network environment gives scholars the right of dynamically controlling information, which not only broaden the depth of interactive content, but also improve the breadth of interaction. However, interactive activity under the network environment is a 
very complex process, if used properly, it will mislead students. So how to implement interactive teaching in the network environment is worth further exploration and research.

\section{References}

[1]Haofeng He. On the teaching design of classroom interaction [J]. Teaching and management, 2002 (7):3-5.

[2]Guang Shi, Shaoxue Zhang, Xiaoqin Luo. The reform of college teaching model and the discussion of interactive teaching mode $[\mathrm{J}]$. Journal of Southwest university for nationalities, 2003 (10):164-168.

[3]Mingyong Lu. A new type of classroom-interactive multimedia network and electronic classroom [J]. Education information, 2003(5).

[4]Dongxing Wu. Research on teaching mode for hybrid learning in the network environment [J]. Chinese audio-visual education, 2008(06):262-264.

[5]Youlan Zhang, Lina Zhang. Study on interactive teaching by using the optical disc resources [J]. Chinese audio-visual education, 2010(02):94-95.

[6]Shaoan Xie. The mental process and strategy of university A/DAS interactive teaching [J]. Education exploration, 2009(8):125-127. 